\title{
Pengolahan Sampah Organik dan Limbah Biomassa dengan Teknologi Olah Sampah di Sumbernya
}

\author{
I Made Indradjaja M. Brunner ${ }^{1,2}$, Arief Norhidayat ${ }^{3}$, Satria M. Brunner ${ }^{4}$ \\ ${ }^{1}$ Electrical Engineering Master Program, Institut Teknologi PLN, Jakarta \\ ${ }^{2}$ Comestoarra Bentarra Noesantarra, Jakarta \\ ${ }^{3}$ Comestoarra Bentarra Noesantarra, Jakarta \\ ${ }^{4}$ Mechanical Engineering, University of Victoria, BC, Canada \\ *Koresponden email: made.brunner@ comestoarra.com
}

Diterima: 1 Juli 2021

Disetujui: 10 Juli 2021

\begin{abstract}
Solid Waste Processing Technology at the Source (TOSS) is an alternative method in processing organic and biomass waste on a communal scale. The processing of organic and biomass waste material is carried out in three stages of the process: biodrying which utilizes the aerobic activity of microorganisms; chopping which is intended to refine the material, and pelletization to compact the material into biomass pellets. The biodrying process in bamboo boxes is able to reduce the water content in organic and biomass waste within 4-5 days. Sorting of non-organic materials can be done at an early stage before or after the biodrying process. Sorting is required before chopping and pelletizing process to avoid unnecessary machine break down. The biomass pellet which is the final product has a diameter of about $10 \mathrm{~mm}$ with a length between $10-40 \mathrm{~mm}$, a calorific value between $3000-4000 \mathrm{kcal} / \mathrm{kg}$, and a moisture content of up to $15 \%$. Compared to coal, biomass pellets tend to have higher volatile and ash content, while lower ash and sulfur content.

Keywords: TOSS, solid waste, biodrying, RDF, biomass pellets
\end{abstract}

\begin{abstract}
Abstrak
Teknologi Olah Sampah di Sumbernya (TOSS) merupakan suatu metode alternatif dalam pengolahan sampah organik dan limbah biomassa pada skala komunal. Pengolahan terhadap material sampah organik dan limbah biomassa dilakukan dengan tiga tahapan proses: biodrying yang memanfaatkan aktivitas aerobik dari mikroorganisma; pencacahan yang ditujukan untuk menghaluskan material; serta peletisasi guna memadatkan material menjadi pelet biomassa. Proses biodrying dalam boks bambu mampu menurunkan kadar air dalam sampah organik dan limbah biomassa dalam waktu sekitar 4-5 hari. Pemilahan terhadap bahan non-organik dapat dilakukan pada tahap awal sebelum atau setelah proses biodrying. Pemilahan perlu dilakukan pada saat sebelum proses cacah dan peletisasi guna mencegah kerusakan pada mesin. Pelet biomassa yang merupakan hasil akhir memiliki diameter sekitar $10 \mathrm{~mm}$ dengan panjang antara 10-40 mm, nilai kalor bakar antara 3000-4000 kkal/kg, dan kadar air setingginya $15 \%$. Dibandingkan dengan batu bara, maka pelet biomassa cenderung memiliki kadar zat terbang dan kadar abu yang lebih tinggi, sedangkan kadar abu dan kadar sulfur yang lebih rendah.
\end{abstract}

Kata Kunci: TOSS, sampah, biodrying, jumputan padat, pelet biomassa

\section{Pendahuluan}

Sampah kini menjadi permasalahan umum yang terjadi di banyak tempat di Indonesia. Kuantitas sampah cenderung bertambah seiring dengan pertambahan jumlah penduduk dan peningkatan taraf hidup. Namun demikian, kemampuan Pemerintah Daerah dalam mengelola sampah seringkali tidak dapat mengimbangi pertumbuhan timbulan sampah tersebut. Berdasarkan data dari SIPSN (Sistem Informasi Pengelolaan Sampah Nasional) - Kementerian Lingkungan Hidup dan Kehutanan, pada tahun 2020 jumlah timbulan sampah nasional mencapai 36,74 juta ton/tahun, dengan 68,05\% sampah dapat terkelola [1]. Fenomena yang disajikan dalam SIPSN ini memberikan gambaran mengenai tingkat pengelolaan sampah di masing-masing daerah. Data SIPSN juga menunjukkan bahwa sampah organik, berupa sisa makanan dan limbah biomassa masih mendominasi hingga sekitar 54\% secara nasional, bahkan di beberapa daerah dapat mencapai lebih dari 60\% [1]. Sebagai salah satu contoh, penelitian di Kota Depok pada tahun 2010 menunjukkan bahwa sampah yang masuk ke Tempat Pemrosesan Akhir (TPA) Cipayung adalah sekitar $56 \%$ dari timbulan sampah kota, dan dari sampah yang masuk ke TPA 63,59\% merupakan sampah organik [2]. 
Sampah organik pada jumlah terbatas memang dapat terdekomposisi menyatu dengan tanah. Prinsip ini yang digunakan dalam pengelolaan sampah organik secara aerobik menjadi material kompos. Kompos merupakan bahan yang dapat memperbaiki struktur dan komposisi tanah yang menyerupai karakteristik humus [3]. Namun demikian, proses pembusukan material organik dapat terdekomposisi secara anaerobik atau tanpa kehadiran oksigen. Proses ini dapat terjadi akibat jumlah limbah biomassa yang berlebih sehingga oksigen di udara tidak dapat mencapai material organik tersebut. Mikroorganisma yang tidak memerlukan oksigen kemudian dapat berkembang dan mendekomposisi material organik. Hasil dekomposisi tersebut akan menghasilkan gas metana yang dapat digunakan sebagai bahan energi. Prinsip ini yang dipakai dalam pengolahan bahan organik menjadi biogas dengan memanfaatkan konsep biodigester [4].

Salah satu metoda pengolahan sampah organik dan limbah biomassa yang dipopulerkan oleh Comestoarra Bentarra Noesantarra (selanjutnya disebut sebagai comestoarra.com) sebuah perusahaan rintisan (startup company) adalah Teknologi Olah Sampah di Sumbernya (TOSS). Metoda ini memanfaatkan sampah organik dan limbah biomassa menjadi bahan bakar nabati dalam bentuk pelet-pelet biomassa. Pelet biomassa ini dapat menjadi alternatif penggunaan bahan bakar batu bara untuk berbagai keperluan [5][6]. Proses yang dilakukan terdiri dari biodrying, pencacahan, dan peletisasi. Hasil pelet biomassa merupakan bahan bakar padat yang memiliki kandungan nilai kalor atau higher heating value (HHV) sekitar 3000-4000 kkal/kg, tergantung ada jenis dan komposisi biomassa.

Paper ini menjelaskan langkah-langkah pemrosesan sampah organik dan limbah biomassa yang sudah dilakukan oleh comestoarra.com di beberapa tempat di Indonesia. Selain itu, tulisan ini juga akan mengungkapkan beberapa hasil penelitian terkait karakteristik dari beberapa campuran material organik yang sudah diubah menjadi bahan bakar padat.

\section{Metode Penelitian}

Pengolahan sampah organik dan limbah biomassa dengan menggunakan TOSS dimaksudkan untuk menjadi suatu konsep pengolahan alternatif dari metode-metode yang sudah berkembang lebih awal. Konsep pengolahan dengan TOSS terdiri dari beberapa langkah utama, yaitu: proses biodrying, pencacahan, peletisasi, dan penanganan produk final. Pemilahan sampah tetap perlu dilakukan untuk menyisihkan sampah-sampah yang bernilai ekonomis, residu yang tidak dapat diolah dengan metode TOSS, serta material pengganggu kinerja mesin cacah dan pelet. Alur pengolahan dengan TOSS disajikan pada Gambar 1.

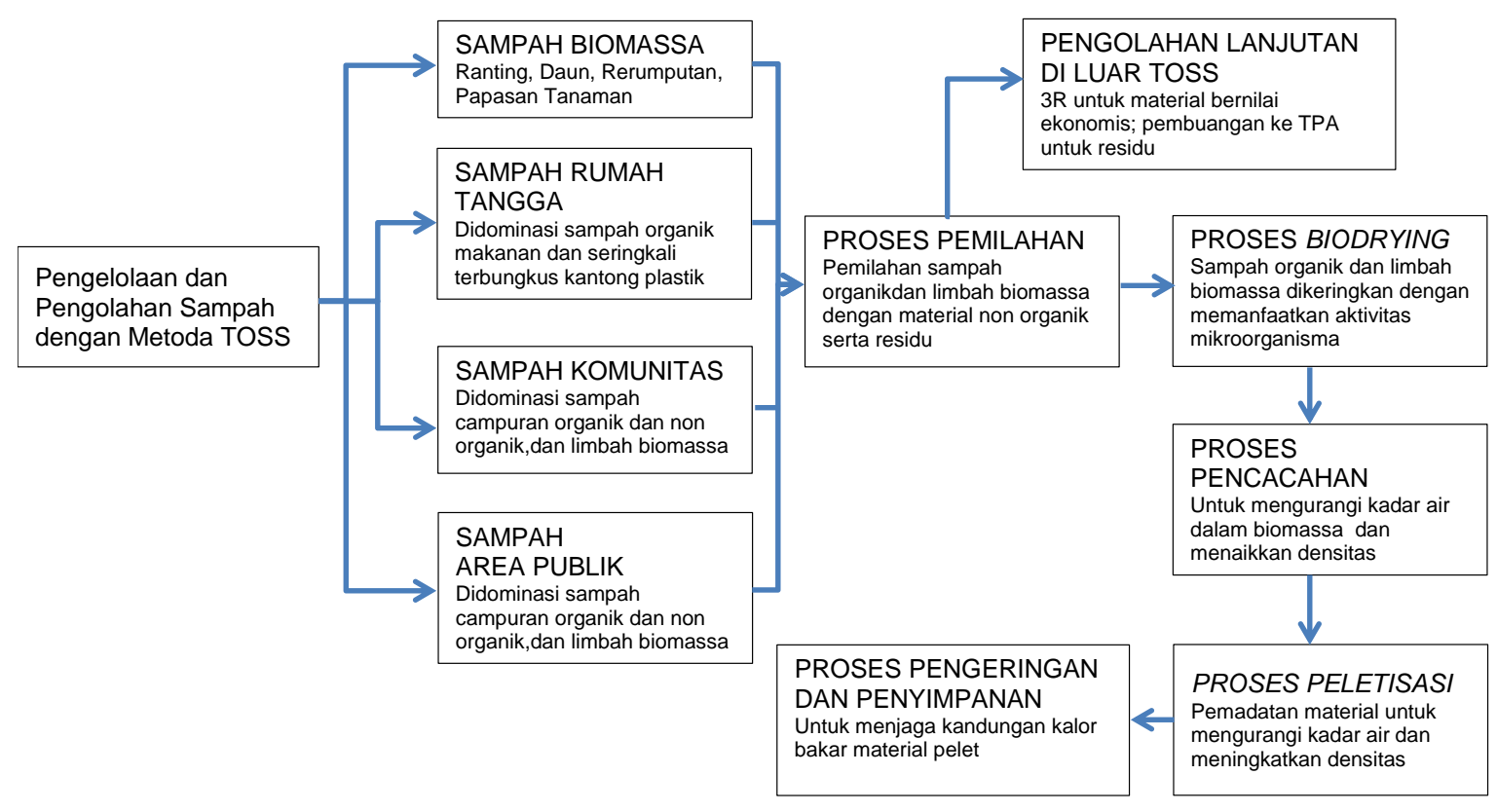

Gambar 1. Alur pengolahan sampah organik dan limbah biomassa dengan TOSS

Metode TOSS menawarkan solusi pengurangan waktu pengolahan sampah organik sehingga dapat menghemat tempat, serta menghasilkan produk akhir berupa bahan bakar padat dalam bentuk pelet 
biomassa. Perbandingan antara pengolahan sampah menjadi kompos dengan proses aerobik, biodigester dengan proses anaerobik, serta TOSS dapat dilihat pada Tabel 1.

Tabel 1. Perbandingan metode pengolahan sampah organik secara biologis

\begin{tabular}{lccc}
\hline & Proses Aerobik* & Proses Anaerobik* & Proses TOSS\# \\
\hline Produk Akhir & Tanah humus, $\mathrm{CO}_{2}, \mathrm{H}_{2} \mathrm{O}$ & Lumpur, $\mathrm{CO}_{2}, \mathrm{CH}_{4}$ & Pelet, Syngas $\left(\mathrm{CO}-\mathrm{H}_{2}\right)$ \\
Waktu Proses & $20-30$ hari & $20-40$ hari & $5-10$ hari \\
Target Utama & Pengurangan volume & Generasi energi & Pengurangan volume \\
Target Tambahan & Produksi kompos & Pengurangan volume, & Generasi energi, stabilisasi \\
& & stabilisasi sampah & sampah \\
Timbulan Bau & Kurang & Ya & Kurang \\
Pemilahan Awal & Diperlukan & Diperlukan & Tentatif \\
\hline
\end{tabular}

* Modifikasi dari Tabel 14-5, [7]

\# Hasil pengamatan lapangan proses TOSS, comestoarra.com

\subsection{Biodrying}

Sampah organik dan limbah biomassa sebelum diproses perlu dipilah terlebih dahulu serta berada dalam keadaan terurai atau tidak terbungkus. Sampah-sampah yang bernilai ekonomis, seperti botol plastik, botol kaca, kaleng, plastik keresek, dan sejenisnya, perlu disisihkan terlebih dahulu. Sampah residu, seperti lampin bekas, masker bekas, bangkai hewan, potongan pipa PVC, karet, serta kain, tidak dapat diolah dengan metode TOSS ini dan perlu disisihkan untuk selanjutnya diproses secara lebih aman atau sebagian dibuang ke TPA. Sementara, sampah terfragmen dalam ukuran kecil seperti potongan plastik keresek, plastik bungkus makanan, dan sejenisnya, dimasukkan terlebih dahulu ke dalam boks bambu untuk dilakukan proses biodrying. Pemilahan tetap dilakukan setelah sampah mengering dan tidak menjijikan lagi.

Teknik biodrying yang digunakan memanfaatkan mikroorganisma yang tersimpan di dalam cairan bioaktivator. Mikroba-mikroba secara aerobik akan melakukan aktivitas penguraian bahan organik. Aktivitas ini akan melepaskan panas yang akan mengurangi kandungan air dalam material namun tetap menjaga nilai kalori di material organik. Bioaktivator diberikan ke sampah domestik dan limbah biomassa di dalam boks bambu berukuran $1 \times 1 \times 1 \mathrm{~m}^{3}$. Bambu menjadi pilihan material untuk dinding dan lantai, dikarenakan bambu merupakan bahan yang banyak tersedia secara lokal, dapat terbaharukan, dan mudah untuk dijadikan bilah-bilah. Selain itu, bambu serta dapat menjaga kestabilan suhu dan sirkulasi udara di dalam boks sehingga menciptakan kondisi yang cocok untuk aktivitas mikroorganisma. Cairan bioaktivator yang dipakai dapat diperoleh di pasaran, seperti EM4, atau yang dikembangkan oleh komunitas, seperti EcoEnzyme. Commestoarra.com juga mengembangkan cairan bioaktivator yang diberi nama AR124, dengan resep sebagaimana disajikan pada Tabel 2. Seluruh bahan dicampurkan dan diendapkan selama sekurangnya 1 minggu. Konsentrat ini dicairkan dengan perbandingan 1:20, untuk kemudian diaplikasikan ke sampah organik dalam 1 boks bambu.

Tabel 2. Resep pembuatan bioaktivator AR124

\begin{tabular}{lc}
\hline \multicolumn{1}{c}{ Bahan } & Kuantitas \\
\hline Molases & $500 \mathrm{~mL}$ \\
Air Kelapa & $1500 \mathrm{~mL}$ \\
Nanas segar (ditumbuk) & $2 \mathrm{Kg}$ \\
Ragi (ditumbuk) & $4 \mathrm{butir}$ \\
Bekatul atau dedak & $300 \mathrm{mg}$ \\
Air & Hingga menjadi $20 \mathrm{~L}$ \\
\hline Sumber: comestoarra.com
\end{tabular}

Rancangan boks bambu yang dipakai untuk proses biodrying disajikan pada Gambar 2. Nampak bahwa dinding dan lantai terbuat dari bilah-bilah bambu yang diberi jarak sekitar 1-1,5 cm di antara bilah untuk sirkulasi udara. Pada salah satu sisi terdapat pintu guna memudahkan pembongkaran material sampah organik dan limbah biomassa yang telah mengering. 


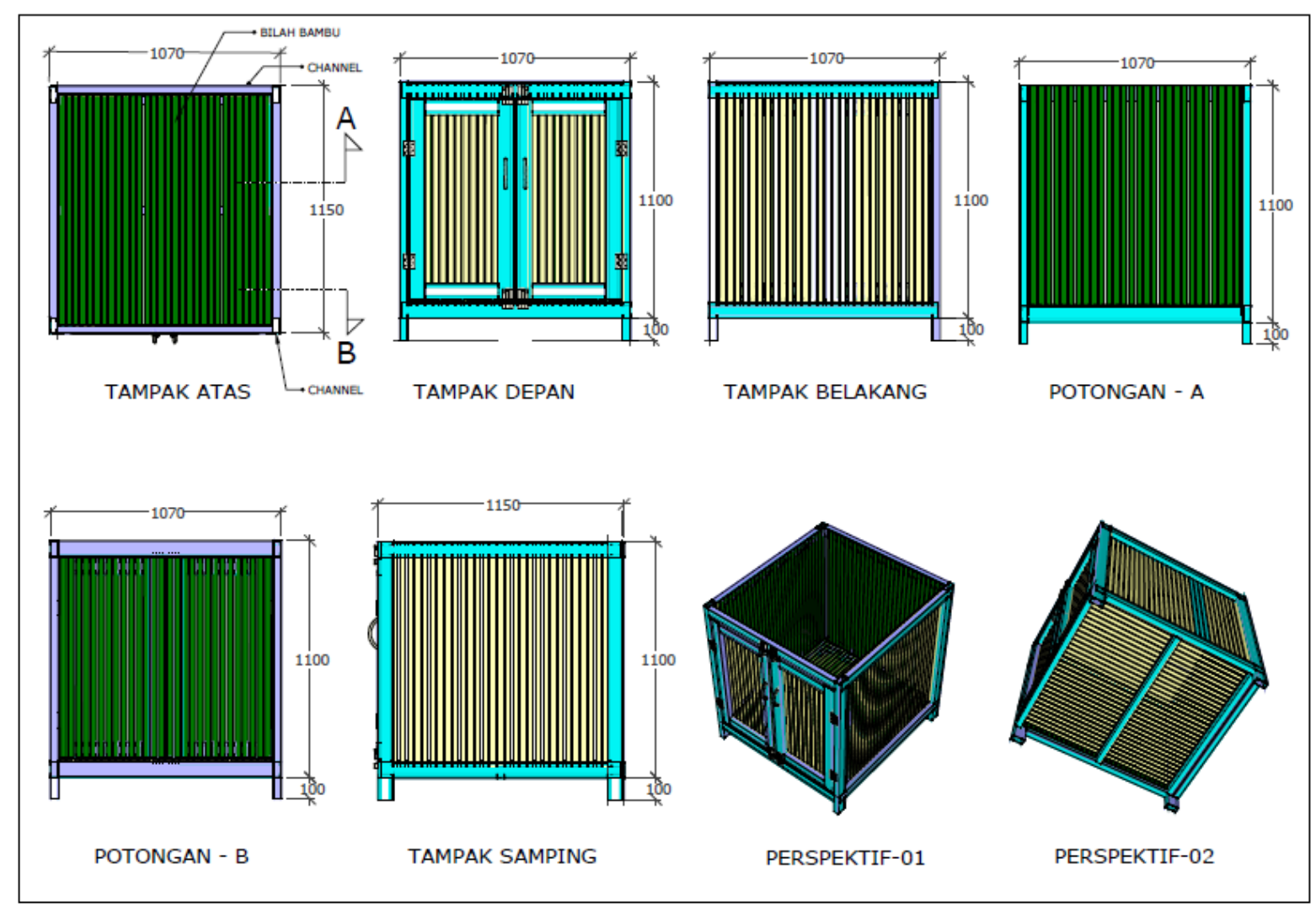

Sumber: comestoarra.com

Gambar 2. Boks bambu untuk proses biodrying

\subsection{Pencacahan}

Proses pencacahan dilakukan setelah material organik mengalami pengeringan hingga hari ke-lima. Pencacahan dilakukan dengan menggunakan mesin cacah yang terdiri dari cutting mills dan hammer mills. Bagian cutting mills terdiri dari rangkaian pisau yang terpasang pada poros yang berputar dan pisau statis. Jarak antara kedua jenis pisau tersebut akan menentukan ukuran hasil pencacahan awal yang akan disalurkan ke bagian hammer mills. Pada bagian ini, potongan material organik akan dicacah dengan serangkaian pisau yang berputar pada poros [8][9]. Pisau-pisau tersebut akan menumbuk material dengan kecepatan tinggi sehingga dapat mengecilkan ukuran hasil cacahan [9][10]. Pada bagian akhir dari mesin cacah, terdapat saringan dengan ukuran yang dapat disesuaikan dengan hasil yang ingin dicapai [11]. Material yang belum lolos dari saringan akan tertahan di ruang hammer mills dan terus mengalami pengecilan ukuran. Pada kegiatan penelitian di lapangan, ukuran filter yang dipakai berdiameter $10 \mathrm{~mm}$. Ukuran ini diyakini cukup untuk memberikan hasil yang dapat dipakai pada proses lanjutan berupa peletisasi.

Sampah yang telah mengering yang dimasukkan ke mesin cacah perlu dipastikan agar terhindar dari material-material pengganggu seperti kaca, besi, karet, kain, plastik, dan material bukan alamiah lainnya. Pemilahan pada tahap ini sangat memerlukan kesabaran dan ketelitian, guna menghindari kerusakan pada mesin cacah serta mengganggu hasil pelet biomassa nantinya. Mesin cacah yang dikembangkan oleh comestoarra.com merupakan hasil temuan dan pengalaman di lapangan selama beberapa tahun. Mesin cacah ini berbeda dengan mesin untuk komposter yang beredar di pasaran, terutama dikarenakan sifat material organik yang masih menyimpan kandungan air di dalam sel-sel, alot, dan berserat. Ilustrasi alat yang dikembangkan dan dipakai pada penelitian lapangan disajikan pada Gambar 3. 


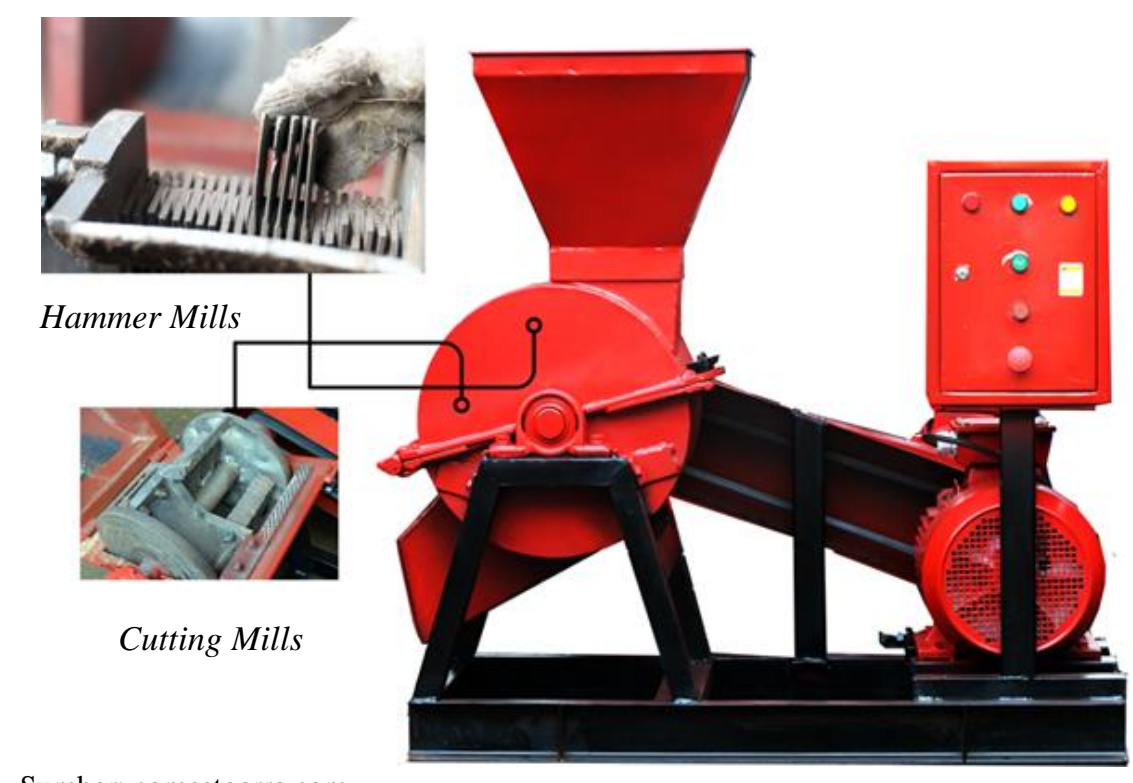

Sumber: comestoarra.com

Gambar 3. Mesin cacah untuk material sampah organik

\subsection{Peletisasi}

Proses peletisasi dilakukan setelah material organik dihaluskan menggunakan mesin cacah. Peletisasi ini dilakukan menggunakan mesin pelet jenis flat die pellet mill [12]. Jenis mesin pelet ini memiliki beberapa komponen utama, termasuk: poros, penggiling, cetakan, dan penyapu [13]. Jenis ini sering dipakai untuk peletisasi biomassa dalam skala kecil [12]. Komponen utama yaitu cetakan bertindak sebagai pembentuk pelet yang dihasilkan [14]. Material hasil cacahan akan ditekan oleh penggiling ke lubanglubang cetakan, kemudian pelet yang sudah padat akan dikeluarkan dari bawah cetakan [12]. Diameter lubang cetakan mesin pelet yang dikembangkan oleh comestoarra.com memiliki diameter $10 \mathrm{~mm}$. Sementara panjang pelet terpotong secara alamiah dengan panjang antara 3-4 cm. Ukuran ini dirancang untuk memenuhi SNI 8966: 2021 tentang Bahan Bakar Jumputan Padat [15].

Material hasil cacahan yang akan dipeletisasi, perlu dipastikan agar terbebas dari material-material pengganggu seperti kaca, besi, karet, kain, plastik, dan material bukan alamiah lainnya. Pemilahan merupakan kunci dalam menjaga kinerja mesin pelet serta hasil pelet biomassa yang dihasilkan. Ilustrasi mesin peletisasi biomassa yang dikembangkan dan dipakai pada penelitian lapangan disajikan pada

\section{Gambar 4.}

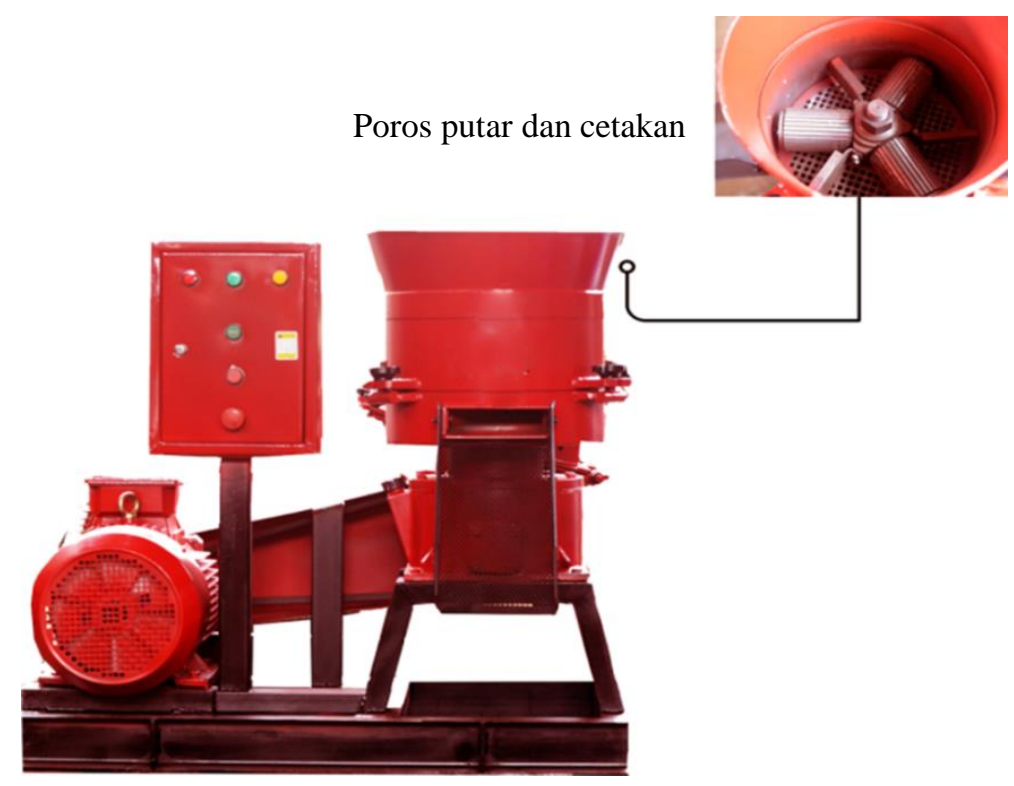

Sumber: comestoarra.com

Gambar 4. Mesin pelet untuk material sampah organik 


\subsection{Finalisasi Produk}

Pelet biomassa yang dihasilkan perlu diangin-anginkan serta dijemur untuk menghilangkan sisa kelembaban. Penjemuran dilakukan di bawah terik matahari selama lebih kurang setengah hari. Pelet kering kemudian diayak untuk menghilangkan potongan kecil-kecil yang akan dikembalikan ke proses peletisasi. Produk pelet yang berdiameter $10 \mathrm{~mm}$ dan panjang antara 3-4 mm kemudian dimasukkan ke dalam karung dan disimpan pada tempat yang kering. Tempat penyimpanan harus terhindar dari hujan serta kelembaban dari tanah dan udara. Pelet biomassa memiliki sifat higroskopis yang cenderung menyerap air dari lingkungan. Penyerapan ini dikarenakan sifat material yang berserat dan mengandung rangkaian hidroksil dari polisakarida yang dikandungnya [16].

Berdasarkan penelitian lapangan, penyerapan air oleh pelet biomassa dapat menurunkan nilai kalori material hingga $100 \mathrm{kkal} / \mathrm{kg}$ untuk setiap kenaikan 1\% kelembaban. Produk pelet biomassa kemudian dianalisis untuk diketahui nilai kalor bakar, serta karakteristik utama lainnya. Uji laboratorium yang serupa dengan uji proksimat dan ultimat batu bara dapat dilakukan untuk pelet biomassa ini.

\section{Hasil dan Pembahasan}

\subsection{Proses Biodrying}

Berdasarkan kajian di lapangan, sampah organik dari kegiatan domestik mengalami penurunan tingkat kelembaban dari $43,50 \%$ menjadi $39,40 \%$ pada hari ke-empat setelah pemberian bioaktivator. Tingkat kelembaban menurun lagi menjadi 32,23\% setelah hari ke-lima. Perubahan tingkat kelembaban ini disajikan pada Gambar 5. Sementara, limbah biomassa berupa ranting, dedaunan, dan potongan tanaman dari perawatan kebun juga diberikan bioaktivator pada awal proses. Tingkat kelembaban awal tercatat sekitar 35,47\% lalu menjadi 30,47\% pada hari ke-empat, dan menurun lagi hingga 23,33\% pada hari kelima. Perubahan tingkat kelembaban ini terlihat pada Gambar 6. Pemanenan hasil untuk kedua material tersebut dilakukan pada hari ke-lima, walaupun proses pengeringan masih terus berjalan pada beberapa hari berikutnya. Material organik tidak perlu dikeringkan terlalu lama, karena pada proses pencacahan terjadi proses pengeringan lanjutan. Penghentian atau pemanenan hasil biodrying pada hari ke-lima dipandang sudah mencukupi dan hal ini dapat menghemat waktu.

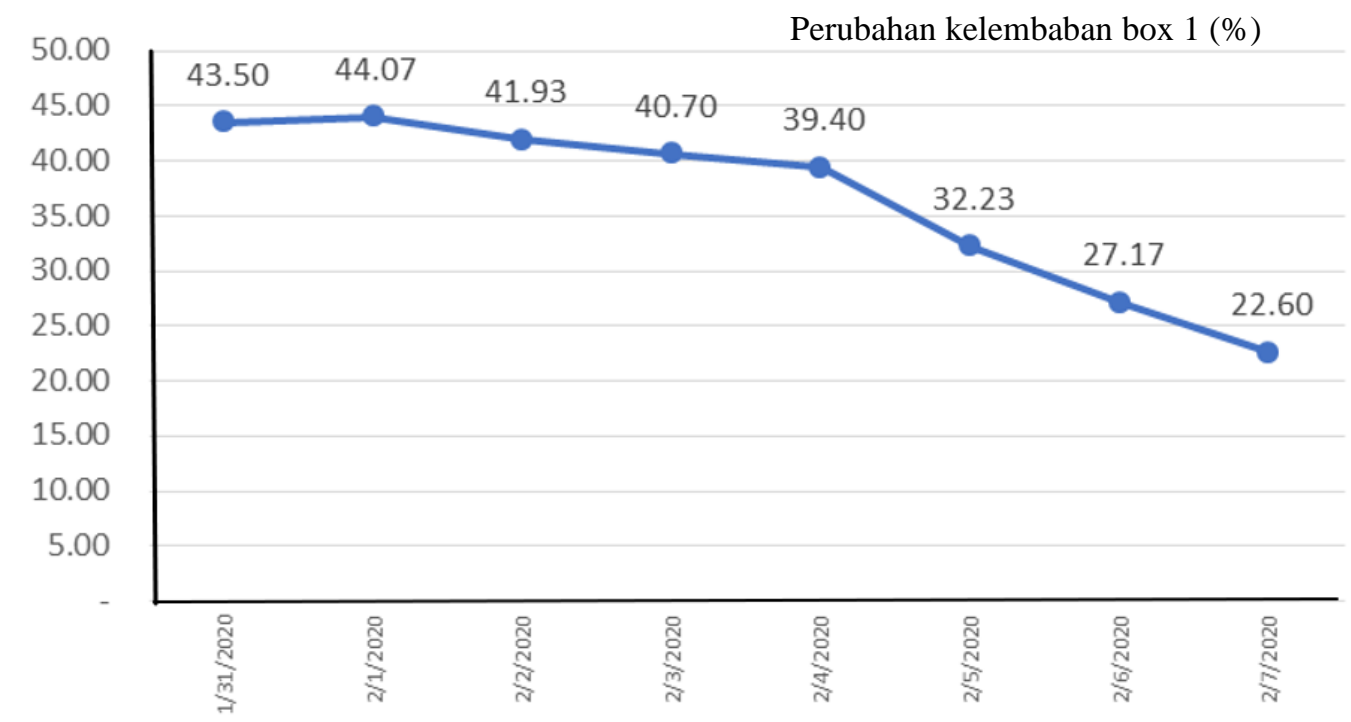

Sumber: comestoarra.com

Gambar 5. Penurunan tingkat kelembaban proses biodrying sampah organik domestik 


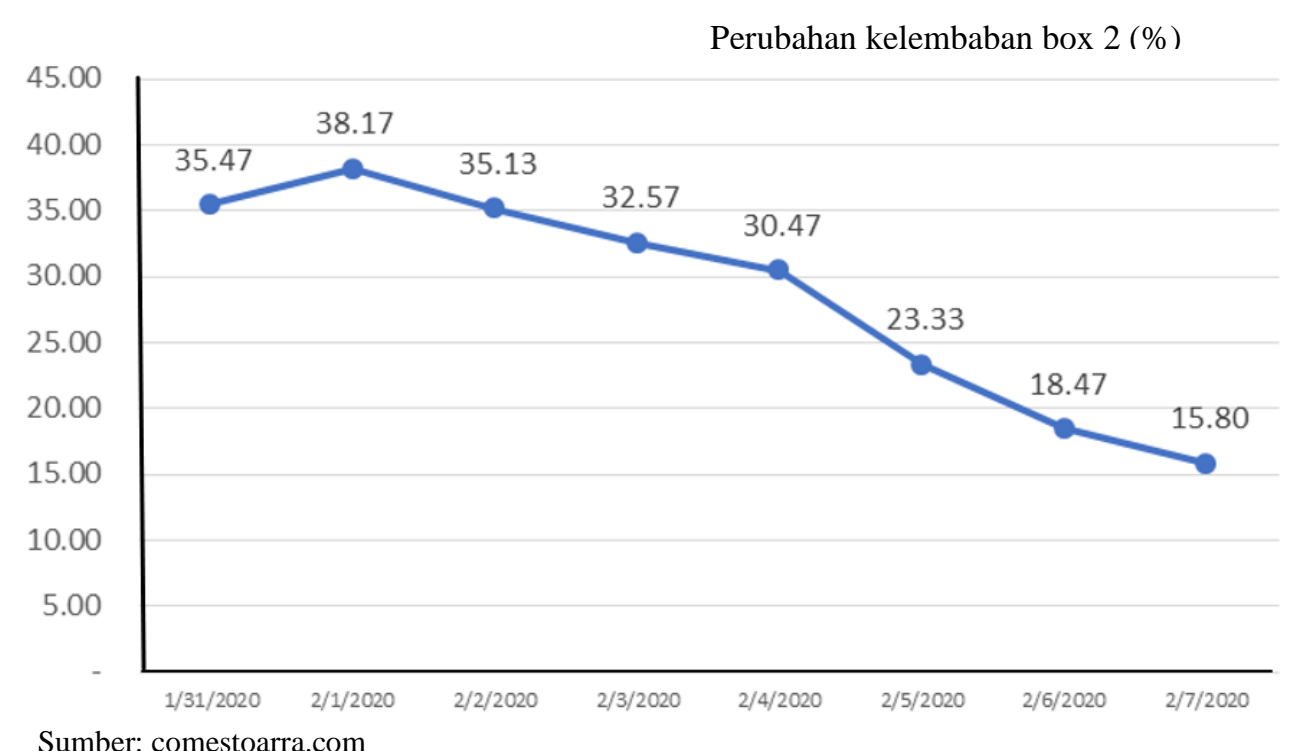

Gambar 6. Penurunan tingkat kelembaban proses biodrying limbah biomassa

Pengukuran tingkat kelembaban dilakukan dengan menggunakan alat ukur kelembaban tanah, atau dengan pengamatan terhadap tingkat susut material. Material yang sudah siap dipanen biasanya terlihat dari penyusutan ketinggian sekitar 30-50\% dari tinggi awal timbunan. Hal penting lain yang perlu dijaga adalah suhu pada timbunan yang tidak boleh melebihi $70^{\circ} \mathrm{C}$. Pengukuran dilakukan dengan menggunakan termometer batang, atau dengan mengamati timbulnya asap dari timbunan. Bila suhu terlalu panas maka perlu dilakukan pengadukan timbunan guna mencegah dekomposisi yang berlebih. Dekomposisi yang terlalu lama akan menurunkan nilai kalor bakar material dan mengubahnya menjadi kompos.

Hasil ini menunjukkan bahwa aktivitas mikroorganisma dapat mengeringkan material organik. Selain itu, ternyata proses ini juga meningkatkan densitas sampah dari sekitar $0,25-0,30$ ton $/ \mathrm{m}^{3}$ menjadi sekitar 0,30-0,35 ton $/ \mathrm{m}^{3}$, serta menghilangkan timbulnya air lindi dan bau. Perhatian khusus perlu diberikan apabila sampah organik yang diperoleh terlalu basah, semisal dari sisa makanan, atau sampah sayuran dan buahan dari pasar. Sampah jenis tersebut perlu ditiriskan terlebih dahulu atau dicampurkan dengan limbah biomassa yang relatif kering, seperti sekam padi, serbuk kayu gergajian, atau rerumputan yang sudah mengering. Bila terlalu basah, maka penambahan bioaktivator akan semakin membuat basah dan menimbulkan belatung-belatung.

\subsection{Proses Pencacahan}

Pencacahan dilakukan terhadap material sampah organik dan limbah biomassa yang sudah mengalami proses biodrying. Material tersebut perlu dipilah secara teliti agar material pengganggu tidak masuk ke mesin cacah. Dari pengamatan di lapangan diperoleh beberapa temuan, di antaranya:

- Cutting mills merupakan salah satu komponen penting dalam pencacahan material sampah organik dan limbah biomassa. Tanpa kehadiran cutting mills maka material yang bersifat alot dan berserat dapat terbelit di pisau-pisau hammer mills. Terlebih apabila hammer mills merupakan rangkaian dari pisaupisau statik seperti yang banyak dipakai pada mesin cacah untuk kompos.

- Cutting mills juga berfungsi untuk menghancurkan material yang keras seperti ranting dan kayu dalam ukuran besar, bilah bambu, tempurung kelapa, dan yang sejenisnya.

- Hammer mills dalam proses pencacahan menimbulkan panas akibat gesekan dengan material. Panas yang ditimbulkan cukup untuk menguapkan kadar air yang masih terkandung pada sampah organik dan limbah biomassa, serta juga dari air dari sel-sel biomassa yang terhancurkan akibat pencacahan.

- Penggunaan filter yang berdiameter $10 \mathrm{~mm}$ atau kurang mudah mengalami penyumbatan, terutama apabila sampah organik dan limbah biomassa yang dicacah memiliki kadar air di atas $60 \%$.

- Material hasil pencacahan memiliki kadar air sekitar 30-40\%, dengan berat jenis sekitar 0,30-0,40 ton $/ \mathrm{m}^{3}$.

\subsection{Proses Peletisasi}

Material hasil pencacahan kemudian dipadatkan dengan alat peletisasi. Pemilahan masih perlu dilakukan agar material pengganggu tidak masuk ke mesin pelet. Dari pengamatan di lapangan diperoleh beberapa temuan, di antaranya: 
- Bahan baku untuk peletisasi perlu dipersiapkan secara benar, baik dari sisi komposisi, kadar air, maupun homogenitas campuran. Kadar air yang baik adalah sekitar 30-35\%. Kadar ini dicapai dengan melakukan pencampuran antara beberapa jenis material, semisal biomassa hasil cacahan dengan serbuk kayu yang relatif kering.

- Hasil pelet yang baik umumnya diperoleh apabila mesin pelet telah berada dalam keadaan panas akibat adanya gesekan antara penggiling dengan piringan cetakan. Panas yang ditimbulkan sangat diperlukan agar kadar air dalam material dapat menguap, serta getah yang terkandung dapat mencair dan bertindak sebagai perekat antar material.

- Kadar air dari pelet biomassa pada saat baru dihasilkan berkisar antara 15-20\%, dan umumnya masih dalam keadaan panas dan berkeringat.

\subsection{Produk Final}

Pelet biomassa yang baru keluar dari mesin pelet masih memerlukan proses penjemuran. Dari pengamatan di lapangan diperoleh beberapa temuan, di antaranya:

- Penjemuran diperlukan agar pelet biomassa dapat mengering hingga memiliki kadar air di bawah $15 \%$. Kadar air yang rendah diperlukan agar pelet menjadi awet, tidak berjamur, serta tidak menjadi lembek karena basah.

- Pelet biomassa yang baik memiliki bentuk seperti silinder dengan diameter sekitar $10 \mathrm{~mm}$ dan panjang antara 10-40 mm, padat dan keras, serta memiliki kadar air sekitar $10-15 \%$, berat jenis sekitar 0,400,50 ton $/ \mathrm{m}^{3}$.

- Hasil pengujian terhadap pelet biomassa di beberapa tempat menunjukkan hasil sebagaimana disajikan pada Tabel 3, dengan penjelasan:

- Nilai kalor bakar pelet biomassa berada pada rentang 3000-4000 kkal $/ \mathrm{kg}$. Pengecualian terjadi untuk serbuk gergajian dari kayu jati dari industri mebel di Jepara yang memiliki nilai kalor hingga $4600 \mathrm{kkal} / \mathrm{kg}$.

- Kadar air dari pelet yang diuji hampir keseluruhan berada pada angka setingginya $15 \%$.

- Kadar sulfur pelet biomassa sekitar 0,06-0,51\%, dengan kadar tertinggi ditemukan pada sampel sekam padi yaitu sekitar $0,51 \%$. Kadar ini relatif masih lebih kecil dibandingkan dengan batu bara yang dapat mencapai kadar: 0,06-1,80\% dengan rata-rata $0,60 \%$ untuk batu bara dari Carsurin, Samarinda [17]; batu bara dari Geoservice, Samarinda yang mencapai kadar rata-rata 1,34\% [18], atau batu bara dari cekungan Illinois, Amerika Serikat yang mencapai 1,2-4,1\% [19].

- Kadar abu pelet biomassa berada pada kisaran 9-37\%, terkecuali serbuk kayu jati yang relatif kecil di kisaran $1,5 \%$. Nampak bahwa sampah domestik yang merupakan campuran dari sisa makanan, potongan sayur, pembersihan tanaman memiliki kadar abu yang tinggi di kisaran 23-37\%. Pelet biomassa pada umumnya memiliki kadar abu yang lebih tinggi dari batu bara yang berkisar antara 8,3-11,5\% untuk batu bara dari cekungan Illinois, Amerika Serikat [19].

- Nilai Zat Terbang (volatile matter) dari pelet biomassa, dengan kisaran 43-80\%, cenderung lebih tinggi daripada batu bara, yang berkisar antara 20-28\% [20].

- Sementara, kadar Karbon Tertambat (fixed carbon) dari pelet, dengan kisaran 8-21\%, cenderung lebih kecil daripada batu bara, yang memiliki kadar antara 22-40\% [20].

Tabel 3. Hasil analisis proksimat terhadap berbagai varian pelet biomassa

\begin{tabular}{|c|c|c|c|c|c|c|c|}
\hline No & Jenis Biomassa & $\begin{array}{c}\text { Kadar } \\
\text { Air } \\
(\%)\end{array}$ & $\begin{array}{c}\text { Zat } \\
\text { Terbang } \\
(\%)\end{array}$ & $\begin{array}{c}\text { Karbon } \\
\text { Tertambat } \\
(\%)\end{array}$ & $\begin{array}{c}\text { Kadar } \\
\text { Abu } \\
(\%)\end{array}$ & $\begin{array}{c}\text { Kadar } \\
\text { Sulfur } \\
(\%)\end{array}$ & $\begin{array}{l}\text { Nilai Kalor } \\
\text { (kkal/kg) }\end{array}$ \\
\hline \multicolumn{8}{|c|}{ Lokasi TOSS Klungkung } \\
\hline 1 & Sampah domestik (Ds. Akah) & 15,24 & 43,40 & 10,19 & 31,01 & 0,16 & 2.922 \\
\hline 2 & Sampah domestik (Ds. Sampalan) & 14,66 & 50,43 & 11,44 & 23,33 & 0,15 & 3.555 \\
\hline \multicolumn{8}{|c|}{ Lokasi TOSS Jepara } \\
\hline 1 & Ilalang & 12,32 & 59,11 & 13,85 & 14,57 & 0,15 & 3.237 \\
\hline 2 & Rerumputan & 12,59 & 54,95 & 14,69 & 17,55 & 0,21 & 3.259 \\
\hline 3 & Serbuk halus kayu jati & 5,99 & 79,82 & 12,59 & 1,54 & 0,06 & 4.624 \\
\hline 4 & Sekam & 7,16 & 55,82 & 11,94 & 24,57 & 0,51 & 3.225 \\
\hline \multicolumn{8}{|c|}{ Lokasi TOSS Yon Armed Bekasi } \\
\hline 1 & Sampah domestik & 5,59 & 49,07 & 7,75 & 37,45 & 0,14 & 3.178 \\
\hline 2 & Kelapa & 8,66 & 54,61 & 21,39 & 15,21 & 0,13 & 3.766 \\
\hline 3 & Bambu & 6,50 & 55,06 & 11,60 & 26,68 & 0,15 & 3.261 \\
\hline
\end{tabular}




\begin{tabular}{|c|c|c|c|c|c|c|c|}
\hline \multicolumn{8}{|c|}{ Lokasi TOSS TPA Kebon Kongok Lombok, NTB } \\
\hline 1 & Mangga (ranting dan daun) & 9,02 & 67,48 & 12,62 & 10,81 & 0,08 & 3.457 \\
\hline 2 & Enceng gondok & 9,19 & 62,88 & 12,20 & 15,73 & $*$ & 3.330 \\
\hline \multicolumn{8}{|c|}{ Lokasi TOSS Ende, NTT } \\
\hline 1 & Limbah biomassa campuran & 10,35 & 68,14 & 12,46 & 9,05 & $*$ & 3.970 \\
\hline
\end{tabular}

Catatan: * kadar tidak diuji

Sumber: comestoarra.com

- Beberapa parameter dari pelet biomassa yang dikembangkan oleh comestoarra.com telah memenuhi beberapa parameter SNI 8966: 2021 tentang Bahan Bakar Jumputan Padat. Perbandingan tersebut disajikan pada Tabel 4. Nampak juga bahwa pelet biomassa masih belum memenuhi persyaratan SNI untuk kelas-kelas tertentu semisal, kadar abu dari sampah domestik cenderung memiliki kadar yang melebihi standar untuk seluruh kelas. Bahkan masih lebih tinggi daripada standar kelas 3 yang mensyaratkan kadar abu di bawah $25 \%$.

Tabel 4. Perbandingan antara pelet biomassa dengan standar bahan bakar jumputan padat

\begin{tabular}{|c|c|c|c|c|c|}
\hline \multirow[t]{2}{*}{ Parameter } & \multirow{2}{*}{$\begin{array}{c}\text { Pelet } \\
\text { Biomassa }\end{array}$} & \multicolumn{3}{|c|}{$\begin{array}{l}\text { SNI 8966: } 2021 \text { tentang Bahan Bakar } \\
\text { Jumputan Padat }\end{array}$} & \multirow[t]{2}{*}{ Catatan } \\
\hline & & Kelas 1 & Kelas 2 & Kelas 3 & \\
\hline Diameter Pelet & $10 \pm 1 \mathrm{~mm}$ & $6-10 \pm 1 \mathrm{~mm}$ & $6-12 \pm 1 \mathrm{~mm}$ & $6-12 \pm 1 \mathrm{~mm}$ & $\begin{array}{l}\text { Dapat memenuhi seluruh } \\
\text { kelas }\end{array}$ \\
\hline Panjang Pelet & $10-40 \mathrm{~mm}$ & $3,15-40 \mathrm{~mm}$ & $3,15-40 \mathrm{~mm}$ & $3,15-40 \mathrm{~mm}$ & $\begin{array}{l}\text { Dapat memenuhi seluruh } \\
\text { kelas }\end{array}$ \\
\hline Kadar Air (\% berat) & $<15 \%$ & $<15 \%$ & $<20 \%$ & $<25 \%$ & $\begin{array}{l}\text { Dapat memenuhi seluruh } \\
\text { kelas }\end{array}$ \\
\hline Kadar Abu ( $\%$ berat) & $9-37 \%$ & $<15 \%$ & $<20 \%$ & $<25 \%$ & $\begin{array}{l}\text { Beberapa jenis biomassa } \\
\text { masih belum memenuhi } \\
\text { standar }\end{array}$ \\
\hline $\begin{array}{l}\text { Kadar Zat Terbang }(\% \\
\text { berat) }\end{array}$ & $43-80 \%$ & $\leq 65 \%$ & $\leq 70 \%$ & $\leq 75 \%$ & $\begin{array}{l}\text { Beberapa jenis biomassa } \\
\text { masih belum memenuhi } \\
\text { standar }\end{array}$ \\
\hline $\begin{array}{l}\text { Kadar Karbon } \\
\text { Tertambat ( } \% \text { berat })\end{array}$ & $8-21 \%$ & $>15$ & $>10$ & $>5$ & $\begin{array}{l}\text { Beberapa jenis biomassa } \\
\text { masih belum memenuhi } \\
\text { standar }\end{array}$ \\
\hline Nilai Kalor (kkal/kg) & $3000-4000$ & 4777 & 3583 & 2389 & Sulit memenuhi kelas 1 \\
\hline Kadar Sulfur ( $\%$ berat) & $0,06-0,51 \%$ & $\leq 1,5 \%$ & $\leq 1,5 \%$ & $\leq 1,5 \%$ & $\begin{array}{l}\text { Dapat memenuhi seluruh } \\
\text { kelas }\end{array}$ \\
\hline
\end{tabular}

Sumber: comestoarra.com

\section{Kesimpulan dan Saran}

\subsection{Kesimpulan}

Pembuatan pelet biomassa dari sampah organik dan limbah biomassa yang dipopulerkan oleh perusahaan rintisan comestoarra.com telah menunjukkan hasil yang nyata. Pelet biomassa telah diproduksi dari kerja keras yang dilakukan di beberapa tempat, seperti di: Kabupaten Klungkung, Bali; Yon Armed di Bekasi, Jawa Barat; TPA Kebon Kongok Lombok, NTB; serta Kabupaten Ende, NTT. Pelet biomassa yang diproduksi dapat menjadi bahan bakar nabati, dengan kalor bakar antara 3000-4000 kkal/kg, tergantung pada jenis dan komposisi sampah organik dan limbah biomassa pembentuknya. Nilai kalor bakar ini kurang lebih setara dengan batu bara muda hingga lignit.

Pelet biomassa bila dibandingkan dengan SNI 8966: 2021 tentang Bahan Bakar Jumputan Padat, terdapat beberapa hal yang dapat didiskusikan, di antaranya bentuk fisik pelet, baik dari diameter maupun panjang, telah memenuhi standar. Selain itu kadar air pelet perlu dijaga agar tetap berada di bawah $15 \%$. Kandungan abu dan karbon tertambat dari pelet biomassa perlu mendapatkan perhatian khusus, terutama apabila berasal dari sampah domestik. Pelet dari sekam dan bambu cenderung memiliki kandungan abu yang relatif tinggi. Sementara, pelet dari hampir semua jenis biomassa, terkecuali kelapa, belum dapat memenuhi standar kelas 1. Nilai kalor bakar dari seluruh jenis biomassa belum dapat memenuhi standar kelas 1 yang mensyaratkan lebih tinggi dari $4777 \mathrm{kkal} / \mathrm{kg}$ atau $20 \mathrm{MJ} / \mathrm{kg}$. Nilai kalor bakar yang mendekati standar tersebut adalah sisa kayu gergajian dari industri mebel di Jepara. Kandungan sulfur pelet biomassa cenderung berada jauh di bawah syarat minimal dari SNI tersebut. 


\subsection{Saran}

Guna menjaga dan meningkatkan kualitas produk pelet biomassa dari comestoarra.com, nampaknya perlu dilakukan beberapa pendekatan, seperti terhadap kadar air pelet biomassa, dengan menjaga tempat penyimpanan yang kering dan terhindar dari hujan dan kelembaban dari tanah dan udara. Tempat penyimpanan harus berada di dalam ruangan dengan lantai yang dilapisi semen atau lantai dari bahan kedap air. Terhadap kadar abu serta kadar karbon tertambat, pencampuran antara hasil cacahan dari sampah domestik dengan limbah biomassa tertentu dapat dilakukan. Komposisi pencampuran yang tepat dapat merupakan fokus penelitian lain agar diperoleh pelet yang memenuhi standar. Sedangkan penggunaan bahan baku kayu yang diharapkan dapat memberikan nilai kalor di atas $4777 \mathrm{kkal} / \mathrm{kg}$ nampaknya memerlukan perhatian khusus. Hal ini berkaitan adanya kemungkinan penggunaan kayu dari hasil alam untuk dijadikan bahan bakar jumputan padat. Penelitian lain kiranya dapat dilakukan untuk mencari limbah biomassa atau lainnya yang dapat menjadi campuran pelet serta dapat meningkatkan nilai kalor bakar.

\section{Ucapan Terima Kasih}

Penulis mengucapkan terima kasih yang mendalam kepada Supriadi Legino dan Djoko Hastowo, selaku inisiator dan pembina TOSS. Ucapan terima kasih juga ditujukan kepada Achmad Rizal Muttaqin, Lalu Aprian Hamdani, Lalu Dani Sapriadi, dan Ivan, selaku tim penggerak TOSS, serta Juni Setiawan dan tim GGS. Tak lupa penulis sampaikan apresiasi kepada seluruh pemangku kepentingan yang telah mendukung kegiatan TOSS di Kabupaten Klungkung, Bali; Yon Armed di Bekasi, Jawa Barat; TPA Kebon Kongok Lombok, NTB. Penghargaan dan rasa persaudaraan yang mendalam kepada Bupati Ende, Manajer PT PLN (Persero) UPK Flores, dan tim TOSS ENDE yang berjuang tanpa mengenal lelah dan penuh semangat.

\section{Referensi}

[1] Kementerian Lingkungan Hidup dan Kehutanan, "Sistem Sistem Informasi Pengelolaan Sampah Nasional (SIPSN)." https://sipsn.menlhk.go.id/sipsn/ (diakses 28 Juni 2021).

[2] F. Zahra and T. Padmi Damanhuri, "Kajian Komposisi, Karakteristik, Dan Potensi Daur Ulang Sampah Di TPA Cipayung, Depok,” J. Tek. Lingkung., vol. 17, no. 1, hal. 59-69, 2011.

[3] A. M. Taiwo, "Composting as a sustainable waste management technique in developing countries," J. Environ. Sci. Technol., vol. 4, no. 2, hal. 93-102, 2011, doi: 10.3923/jest.2011.93.102.

[4] C. D. S. Guimarães, D. R. D. S. Maia, and E. G. Serra, "Construction of biodigesters to optimize the production of biogas from anaerobic co-digestion of food waste and sewage," Energies, vol. 11, no. 4, 2018, doi: 10.3390/en11040870.

[5] S. Legino, R. Hidayawanti, and I. Wirantika, "Waste as fastest cycle of renewable energy sources through TOSS Model," J. Phys. Conf. Ser., vol. 1282, no. 1, hal. 1-7, 2019, doi: 10.1088/17426596/1282/1/012041.

[6] S. Legino, R. Hidayawanti, I. S. Putra, and A. Pribadi, "Reducing coal consumption by people empowerment using local waste processing unit," J. Phys. Conf. Ser., vol. 1217, no. 1, hal. 1-9, 2019, doi: 10.1088/1742-6596/1217/1/012028.

[7] H. Vigil, S., Tchobanoglous, G., Theisen, Integrated solid waste management: engineering principles and management issues. United Kingdom: McGraw-Hill Companies,Incorporated., 1993.

[8] R. Zulkarnain, S. Slamet, and T. Hidayat, "Perancangan mesin hammer mill penghancur bongkol jagung dengan kapasitas $100 \mathrm{~kg} / \mathrm{jam}$ sebagai pakan ternak," Snatif, hal. 75-82, 2014.

[9] M. Gil and I. Arauzo, "Hammer mill operating and biomass physical conditions effects on particle size distribution of solid pulverized biofuels," Fuel Process. Technol., vol. 127, hal. 80-87, 2014, doi: 10.1016/j.fuproc.2014.06.016.

[10] S. Kurniawan and A. Kusnayat, "Perancangan Hammer Pada Mesin Hammer Mill Menggunakan Metoda Discrete Element Modelling Untuk Meningkatkan Kehalusan Penggilingan Kulit Kopi," J. Rekayasa Sist. Ind., vol. 3, no. 4, hal. 21-24, 2016.

[11] L. J. Naimi et al., "Modeling and characterization of biomass size reduction," in 2007 ASABE Annual International Meeting, Technical Papers, 2007, vol. 076047, hal. 1-16, doi: 10.13031/2013.23432.

[12] R. Rajbhar, S. Sapate, N. Sarawade, S. Wankhede, and A. S. Bongade, "Analysis \& Development of Flat Die of Biomass Pellet Machine," Int. Res. J. Eng. Technol., vol. 6, no. 5, hal. 4720-4725, 2019, [Online]. Available: www.irjet.net. 
[13] G. J. C. Bartolome, S. M. C. de Leon, C. A. Polinga, and J. M. B. Roño, "Design, fabrication, and testing of biomass pelleting machine for coffee wastes," IOP Conf. Ser. Earth Environ. Sci., vol. 633, no. 1, 2021, doi: 10.1088/1755-1315/633/1/012002.

[14] S. K. Nielsen, M. Mandø, and A. B. Rosenørn, "Review of die design and process parameters in the biomass pelleting process," Powder Technol., vol. 364, hal. 971-985, 2020, doi: 10.1016/j.powtec.2019.10.051.

[15] Standar Nasional Indonesia, "SNI 8966: 2021 Bahan Bakar Jumputan Padat.” 2021.

[16] H. Gilvari, L. Cutz, U. Tiringer, A. Mol, W. de Jong, and D. L. Schott, "The effect of environmental conditions on the degradation behavior of biomass pellets," Polymers (Basel)., vol. 12, no. 4, hal. 115, 2020, doi: 10.3390/POLYM12040970.

[17] N. M. Agung N, W. Nugroho, and H. Hasan, "Hubungan Kandungan Total Sulphur Terhadap Gross Calorific Value Pada Batubara PT. Carsurin Samarinda," J. Teknol. Miner. FT UNMUL, vol. 7, no. 1, hal. 1-8, 2019.

[18] A. Artiningsih, S. Widodo, and A. Firmansyah, "Studi Penentuan Kandungan Sulfur (Sulphur Analysis) Dalam Batubara Pada PT Geoservices Samarinda,” J. Geomine, vol. 02, hal. 68-71, 2015.

[19] M. Rostam-Abadi., "Development of carbon-based adsorbents for removal of mercury emissions from coal combustion flue gas," Stud. Surf. Sci. Catal., vol. 120 A, hal. 459-483, 1999, doi: 10.1016/s01672991(99)80561-8.

[20] S. Aich, D. Behera, B. K. Nandi, and S. Bhattacharya, "Relationship between proximate analysis parameters and combustion behaviour of high ash Indian coal," Int. J. Coal Sci. Technol., vol. 7, no. 4, hal. 766-777, 2020, doi: 10.1007/s40789-020-00312-5. 